\title{
EDUKASI KESEHATAN REPRODUKSI REMAJA GENERASI Z DENGAN METODE EDUGAME DI SMA 1 BATANG ANAI, PARIAMAN
}

\section{THE EDUCATION OF HEALTH REPRODUCTION OF YOUTH Z GENERATION BY EDUGAME METHOD AT SMA 1 BATANG ANAI, PARIAMAN}

\author{
Biomechy Oktomalioputri $^{1{ }^{1 *}}$, Eryati Darwin ${ }^{2)}$ Dina Arfiani Rusjdi $^{3)}$, Nita Afriani ${ }^{4),}$ Roza \\ Silvia $^{5)}$, Malinda Meinapuri' ${ }^{6}$, Tuti Handayani ${ }^{7}$, Yulia Kurniawati $^{8)}$, Novita Aryani ${ }^{6}$, \\ Lila Indrati $^{7)}$, Fathiya Juwita Hanum ${ }^{8)}$, Noverial' ${ }^{9)}$, Meutia Savitri ${ }^{10)}$ \\ 1)*Fakultas Kedokteran, Universitas Andalas, Padang, email : biomechyolivia@yahoo.com \\ $\left.{ }^{2-10}\right)$ Fakultas Kedokteran, Universitas Andalas, Padang
}

\begin{abstract}
ABSTRAK
Generasi $Z$ atau yang dikenal generasi-net, generasi remaja yang akan meneruskan generasi milenial saat ini diharapkan dapat membuat era baru dalam perkembangan teknologi. Dengan pengaruh yang kuat dari teknologi internet ditakutkan tidak hanya mengubah pola pikir generasi $z$ tetapi dapat pula menjadikan sesuatu yang tabu menjadi tradisi yang ilegal dikalangan masyarakat. Seperti berkembangnya kelompok lesbian, gay, biseksual, dan transgender atau yang dikenal dengan sebutan LGBT. Badan Perencana Pembangunan Daerah Sumatera Barat melakukan survey di akhir 2017, Provinsi Sumatera Barat (Sumbar) menjadi daerah terbanyak di Indonesia yang dihuni oleh kelompok LGBT. Diperkirakan angka sementara mencapai puluhan ribu LGBT di Sumbar. Daerah Padang Pariaman memiliki kasus LGBT terbanyak setelah kota Padang. Kegiatan edukasi terkait kesehatan reproduksi yang dikemas dengan baik dan menarik diharapkan mampu memberikan pengetahuan yang cukup untuk remaja agar tidak sampai melakukan hal-hal yang akan mengganggu kesehatan reproduksinya kelak. Kegiatan tersebut telah dilaksanakan oleh Tim Pengabdian Masyarakat Bagian Histologi dan Radiologi Fakultas Kedokteran Universitas Andalas yang berjudul "Edukasi Kesehatan Reproduksi Remaja generasi $z$ dengan metode edugame pada Siswa SMA 1 Batang Anai, Padang Pariaman. Pada pengabdian masyarakat ini didapatkan hasil bahwa siswa memiliki persamaan persepsi mengenai bahaya LGBT dan free sex. Metode edugame dan penyuluhan yang disertai dengan video animasi ini menjadi salah satu kegiatan persuasif dengan metode efektif yang dapat mengajak siswa agar menyadari bahaya LGBT dan free sex.
\end{abstract}

Kata kunci : Edukasi kesehatan reproduksi, Generasi Z, Metode edugame

\section{ABSTRACT}

Generation Z, or which is well known as net-generation, the generation of adolescent that will continue the current millennial generation is expected to create a new era in technological development. Due to the strong influence of technology, the internet is feared not only can change the mindset of generations, but also can turn something taboo into an illegal tradition among citizen, such as the development of lesbians, gays, bisexuals, and transgender people, also known as LGBT. The West Sumatra Regional Development Planning Agency conducted a survey at the end of 2017. It is obtained that West Sumatra is the largest province in Indonesia inhabited by LGBT groups. It is estimated temporary numbers reach tens of thousands of LGBT in West Sumatra. Padang Pariaman district has the most LGBT cases after Padang city. Educational, well-packaged and interesting health activities are needed to provide enough knowledge for adolescents to avoid doing things that will interfere their reproductive health later. This activity has been implemented by community service team held by the Histology and Radiology Department of Faculty of Medicine Andalas University entitled "Education of Adolescent Reproductive Health for Generation $Z$ with Edugame 
method for students of Senior High School 1 Batang Anai, Pariaman”. In this community service activity is obtained students have the same perception about the dangers of LGBT and free sex. Edugame method and counseling with animated videos is one of the effective methods to attract students sto aware the dangers of LGBT and free sex.

Keywords : Reproductive Health Education, Generation Z, Edugame Method

\section{PENDAHULUAN}

Usia remaja merupakan usia transisi dari anak ke usia dewasa. Pada usia ini terjadi perubahan fisik maupun psikologis. Usia remaja saat ini dikenal dengan sebutan Generasi $Z$ atau generasi-net. Generasi remaja yang akan meneruskan generasi milenial saat ini diharapkan dapat membuat era baru dalam perkembangan teknologi. Tetapi generasi ini pun dikhawatirkan dapat mengubah moral yang ada sejak zaman nenek moyang. Dengan pengaruh yang kuat dari teknologi internet ditakutkan tidak hanya mengubah pola pikir generasi $z$ tetapi dapat pula menjadikan sesuatu yang tabu menjadi tradisi yang ilegal dikalangan masyarakat. Seperti berkembangnya kelompok lesbian, gay, biseksual, dan transgender atau yang dikenal dengan sebutan LGBT.

Badan Perencana Pembangunan Daerah Sumatera Barat melakukan survey di akhir 2017, Provinsi Sumatera Barat (Sumbar) menjadi daerah terbanyak di Indonesia yang dihuni oleh kelompok Lesbian, Gay, Biseks dan Transgender. Diperkirakan angka sementara mencapai puluhan ribu LGBT di Sumbar. Daerah Padang Pariaman memiliki kasus LGBT terbanyak setelah kota Padang.

Gaya pergaulan bebas yang samakin hari semakin meluas di kalanan remaja, dikhawatirkan akan menambah deretan masalah seperti HIV/AIDS dan penyakit menular seksual lainnya, kehamilan yang tak diharapkan, kecenderungan ke arah penyuka sesama jenis, dan lain-lain.

Berdasarkan identifikasi masalah diatas maka didapatkan suatu permasalahan:

1. Angka kejadian masalah terkait pergaulan bebas dan LGBT pada remaja selalu meningkat setiap tahunnya

2. Masih rendahnya pemahaman yang benar pada remaja tentang pergaulan bebas dan LGBT serta masalah yang ditimbulkannya.

3. Masih sedikit sarana edukasi kesehatan reproduksi bagi remaja, terutama siswa/siswi SMA

4. Masih belum banyak data akurat terkait masalah kesehatan reproduksi khususnya pergaulan bebas dan LGBT pada remaja

5. Penyalahgunaan media internet oleh remaja

\section{METODE PELAKSANAAN KEGIATAN}

Kegiatan ini dilaksanakan di SMA 1 Batang Anai Padang Pariaman dengan sasaran siswa kelas 1 dan 2 SMA 1 Batang Anai, Padang Pariaman.

Program ini bertujuan Memberikan edukasi kepada siswa SMA 1 Batang Anai mengenai kesehatan reproduksi remaja khususnya pergaulan bebas dan LGBT dengan media internet dengan metode pendekatan edugame serta memotivasi siswa SMA 1 Batang Anai agar bisa menjadi 
remaja yang sadar kesehatan reproduksi

khususnya pergaulan bebas dan LGBT, serta

bisa menyebarkan juga pemahaman dan

kesadaran tersebut ke sesama remaja lain dalam kelompoknya

Ada beberapa metode pendekatan yang digunakan dalam pelaksanaan PKM (dimulai dari persiapan sampai kegiatan berlangsung )

1. Melakukan persiapan meliputi koordinasi dengan mitra sekolah untuk penetapan tempat dan lokasi, jadwal survey dan penyuluhan, persiapan peralatan saat turun lapangan dan kesiapan mitra menerima penyuluhan.

2. Melakukan survei awal kepada siswa tentang perilaku mereka terkait pergaulan bebas bebas dan LGBT . Survei dilakukan dengan menggunakan metode Kahoot berisi pertanyaan singkat menjaring perilaku seksual beresiko dari pergaulan sehari-hari remaja. Survei dilakukan pada siswa kelas 1 dan kelas 2 .

3. Penyuluhan terhadap siswa terkait pergaulan bebas dan LGBT dan diakhiri dengan penanyangan video animasi mengenai bahaya LGBT dan free sex

4. Edugame dengan membuat Focused Group Discussion dimana siswa dibagi menjadi 5 kelompok dan akan membahas suatu topik dan dipresentasikan di depan audience

Penyuluhan dilakukan terhadap 60 orang siswa yang merupakan siswa/siswi terpilih dari kelas 1 dan kelas 2. Tujuan dipilih siswa/siswi seperti ini adalah agar pada saat pemberian penyuluhan, mereka mampu mengikuti dengan baik, lalu kemudian dapat menyebarkannya ke teman-temannya dan menjadi agen perubahan di kelompoknya sehari-hari, baik di kelas masing-masing ataupun di sekolahnya. Kegiatan ini dibagi lagi ke dalam 4 sesi, yaitu :

1. Kuis online

Kuis diberikan sebelum diskusi kelompok diadakan. Pemberian kuis dikemas dengan media secara online dengan metode $\mathrm{Ka}$-Hoot

2. Focused group discussion (FGD) Dengan membentuk kelompok diskusi dengan membahas topik yang telah diberi narasumber.

Masing-masing kelompok terdiri atas 10 12 orang siswa. Siswa dalam kelompok berdiskusi dipimpin ketua (salah seorang siswa) dan didampingi fasilitator (dosen). Setiap pendapat dari anggota kelompok dicatat oleh sekretaris (salah seorang siswa juga).

3. Diskusi Pleno

Ketua masing-masing kelompok memaparkan hasil diskusi kelompoknya di depan semua peserta untuk kemudian mereka saling mengklarifikasi atau berdiskusi secara bersama-sama.

\section{Pengarahan dari narasumber}

Narasumber mengklarifikasi hasil diskusi siswa terkait hal-hal teoritis sehubungan dengan masalah yang diangkat sebagai skenario, serta pemahaman lainnya terkait 
topik pergaulan bebas dan LGBT pada masalah, hal ini dilakukan dengan tujuan agar remaja.

\section{HASIL DAN PEMBAHASAN}

Kegiatan pengabdian masyarakat di SMA 1 Batang Anai mendapatkan hasil sebagai berikut :

\section{Kuis Ka-Hoot}

Dari hasi kuis didapatkan berbagai variasi jawaban dari siswa mengenai tata cara bergaul sampai pandangan mereka mengenai :LGBT dan free sex
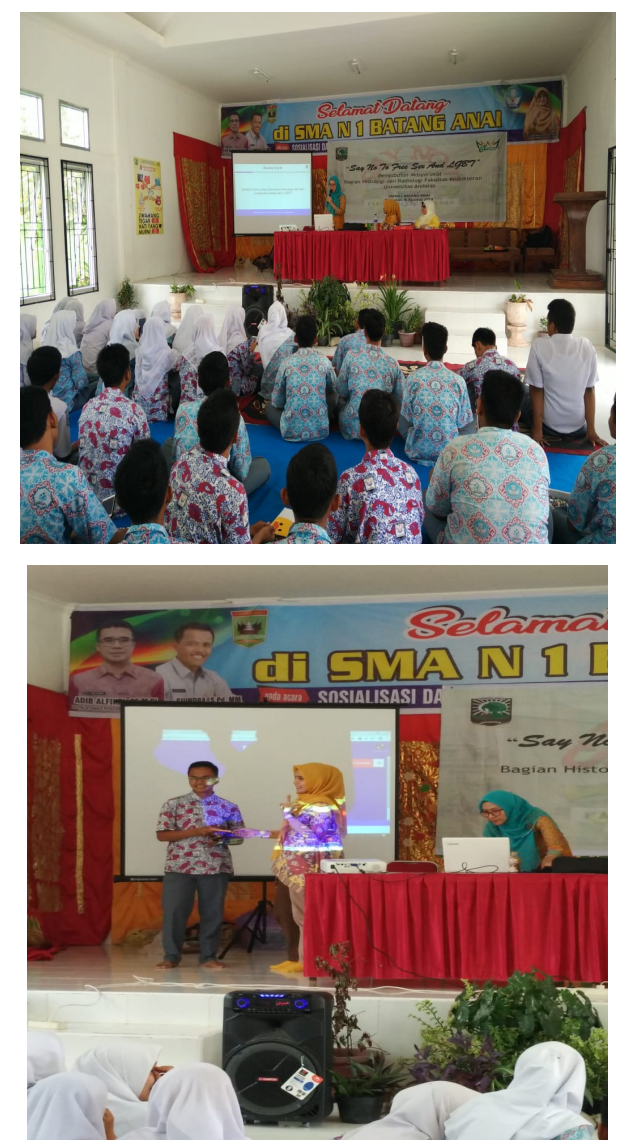

2. Focused group discussion (FGD)

Siswa dibagi menjadi 5 kelompok. Masing-masing kelompok mendiskusikan topik mengenai "pacaran" untuk dicari apa saja sisi positif dan negatifnya yang dituangkan dalam bentuk pohon pemecah setiap pokok permasalahan baru yang muncul setalah diskusi kelompok akan dibahas kembali oleh kelompok tersebut sampai tidak ditemukan lagi permasalahan. selanjutya dilakukan penarikan kesimpulan dari hasil diskusi dam kelompok dan akan dipresentasikan nantinya.

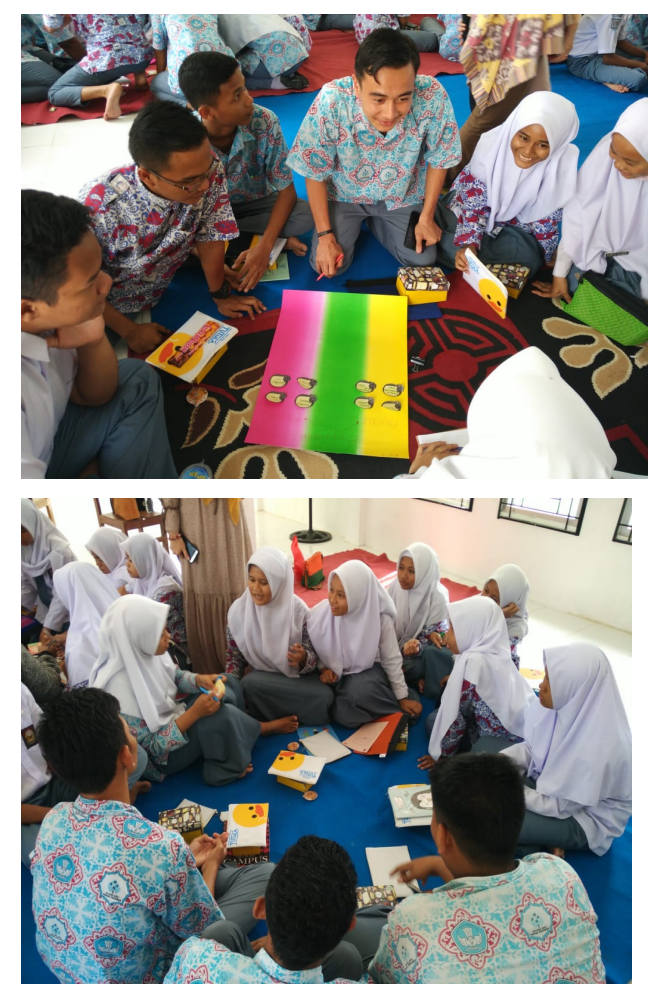

3. Diskusi Pleno

Hasil dari diskusi kelompok siswa dipresentasikan di depan teman-teman siswa, dan secara bergantian siswa memberikan tanggapan mengenai hasi diskusi dari kelompok presentant. 

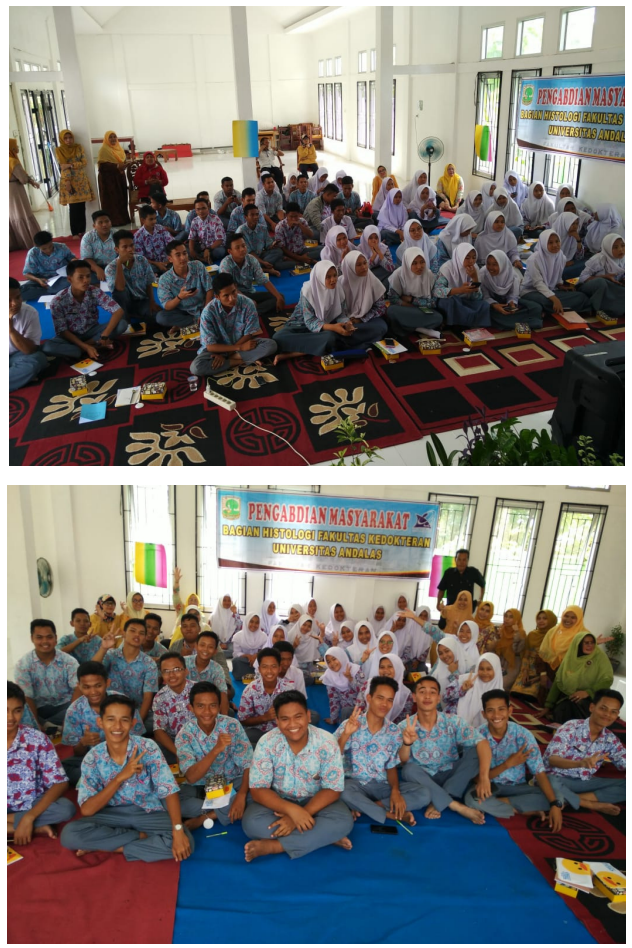

4. Pengarahan dari narasumber

Setelah beberapa tahap kegiatan dan diakhiri dengan pengarahan dari narasumber didapatkan hasil bahwa siswa sependapat berpacaran memiliki sisi negatif yang lebih banyak dibandingkan dengan sisi positif. Siswa juga sependapat bahwa LGBT dan free sex tidak diperbolehkan, "Say no to LGBT and Free Sex"

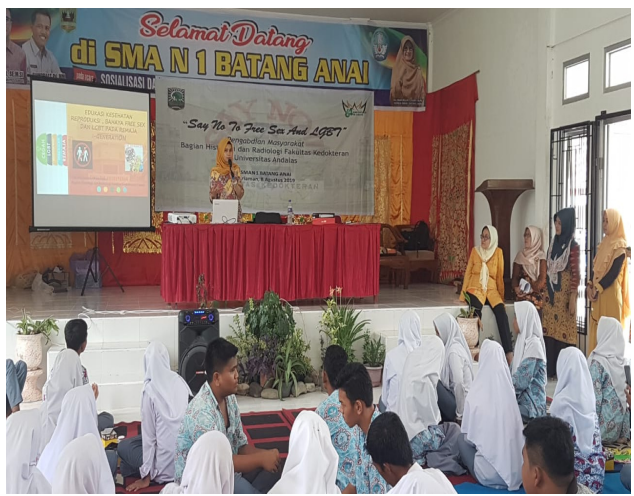

5. Pemberian modul

Diakhir acara tim pengabdian masyarakat memberikan kenang-kenangan berupa modul mengenai kesehatan reproduksi remaja dan diserahkan kepada pihak sekolah.
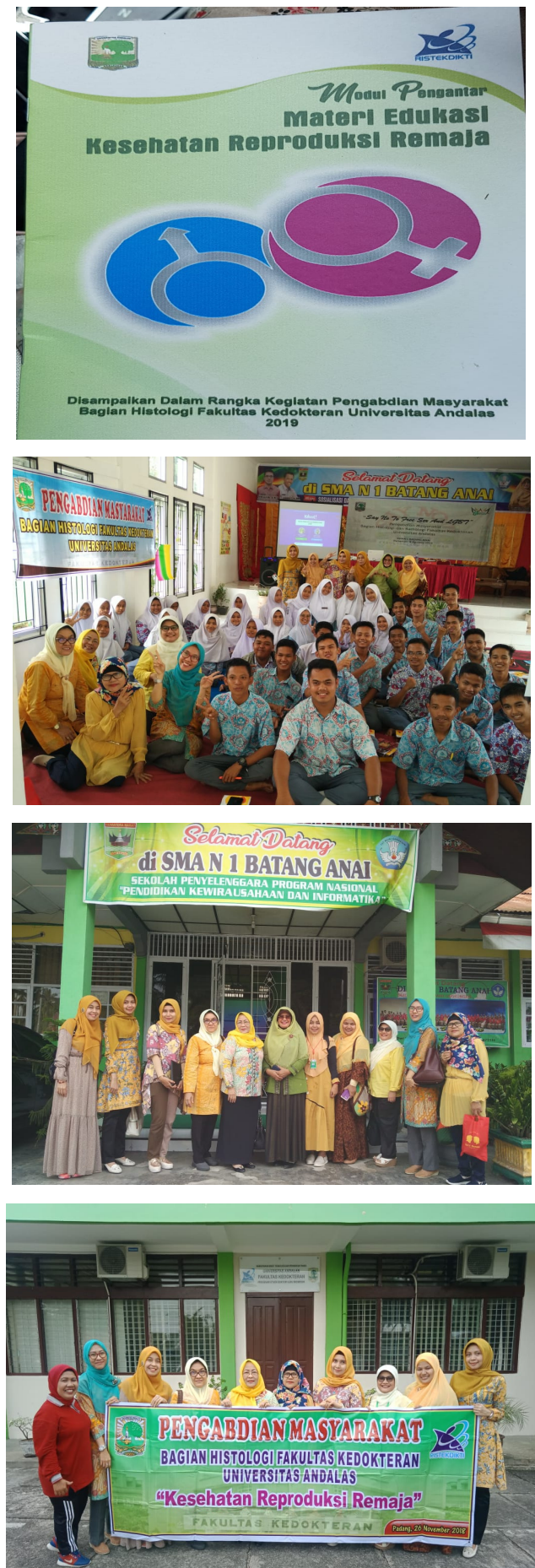
KESIMPULAN

Kegiatan Pengabdian masyarakat yang dilakukan oleh tim pengmas dari bagian histologi dan radiologi fakultas kedokteran mendapatkan hasil

1. Siswa memiliki persamaan persepsi mengenai bahaya LGBT dan free sex

2. Metode edugame ini merupakan salah satu metode yeng efektif sebagai daya tarik siswa agar materi yang kita sampaikan tidak membosankan dan dapat mereka terima.

3. Penyuluhan yang disertai dengan video animasi membuat siswa lebih tertarik untuk mengikuti kegiatan ini

\section{SARAN}

Kegiatan ini juga diharapkan dapat memberikan masukan terhadap sekolah untuk menerapkan pendidikan berkarakter dan pendidikan kesehatan reproduksi remaja secara kontiniu agar terciptanya generasi penerus yang berpikiran positif dan bebas dari bahaya pergaulan bebas dan LGBT.

\section{UCAPAN TERIMAKASIH}

Tim Pengabdian Masyarakat bagian Histologi dan Radiologi mengucapkan terima kasih kepada Kepala Sekolah SMA 1 Batang Anai, Padang Pariaman yang telah menyambut tim dan memfasilitasi sekolah dalam kegiatan pengabdian masyarakat ini.

Tak lupa pula untuk siswa-siswi tercinta SMA1 Batang Anai yang tetap semangat dan memiliki antusias tinggi dalam mengikuti acara kegiatan dari awal sampai akhir.

Tim juga mengucapkan banyak terima kasih kepada tim pengelola Jurnal LOGISTA Departement of Agricultural Product Technology, Faculty of Agricultural Technology, Universitas Andalas atas kerjasamanya dalam publikasi artikel ini.

\section{REFERENSI}

[1] Badan Pusat Statistik. 2009. Statistik Indonesia. Badan Pusat Statistik. Jakarta

[2] Badan Pusat Statistik (BPS). 2015. Profil Penduduk Indonesia Hasil Supas 2015. Jakarta : BPS

[3] Batubara, J.(2010). Adolescent Development (Perkembangan Remaja) saripediatri.idai.or.id

[4] Eny Kusmiran. (2011). Kesehatan Reproduksi Remaja Dan Wanita. Jakarta; Salemba Medika.

[5] Rizki, N.A. (2012). Metode Focus Group Discussion dan Simulation Game Terhadap Peningkatan Pengetahuan Kesehatan Reproduksi. Jurnal Kesehatan Masyarakat. MaretJuli 2012:23-29. ISSN 1858-1196

[6] Widyastari D,dkk (2008). Remaja Dalam Bahaya Pengaruh Paparan Internet Dan Faktor Lain Terhadap Sikap Seksual Remaja. Jurnal kesehatan reproduksi vol. 1 no 1. Desember 2010. 